\title{
Source governed trace metal anomalies in groundwater of foothill aquifer and its health effect
}

\author{
Banajarani Panda ${ }^{1} \cdot$ S. Chidambaram ${ }^{2} \cdot$ R. Thilagavathi $^{1} \cdot$ N. Ganesh ${ }^{1} \cdot$ M. V. Prasanna ${ }^{3}$ (i) $\cdot$ U. Vasudevan ${ }^{1}$
}

Received: 6 July 2018 / Accepted: 11 June 2020 / Published online: 26 June 2020

(C) The Author(s) 2020

\begin{abstract}
An integrated study of health risk assessment, pollution indices and cluster analysis has been carried out to assess the pollution and heavy metal sources in the groundwater. Certain elements analyzed exceed the prescribed limits of WHO standard. Health risk index reveals risk of toxicity through oral pathways is less, as almost all trace elements are $<1$. The distribution pattern of heavy metal pollution index, heavy metal evaluation index and degree of contamination indicates the pollution is due to urban activities. Sources were determined by cluster analysis, and it resulted in three clusters.
\end{abstract}

Keywords Metals $\cdot$ Health risk index $\cdot$ Pollution index $\cdot$ Cluster analysis $\cdot$ Degree of contamination

\section{Introduction}

Groundwater is an indispensable natural resource and plays a promising role to meet the domestic, industrial as well as crop water requirements due to its desirable high quality. The contamination of water with potentially toxic heavy metal is a significant ecological problem in both developed and developing countries (Khan et al. 2013). Trace metals are dangerous to aquatic ecosystem as it is toxic and have a greater tendency to integrate with food chain (Abolude et al. 2009). Several trace elements from agricultural, industrial, domestic and urban wastes may infiltrate into the aquifer through leaching (Biney and Christopher 1991). Because of infiltration, groundwater pollution happens to a great extent and influences the rural as well as urban area drinking water (Thuyet et al. 2016). Human health condition can be a key factor to evaluate the risk level postured by various pollutants (Wu et al. 2010).

M. V. Prasanna

geoprasanna@gmail.com

1 Department of Earth Sciences, Annamalai University, Annamalai Nagar 608002, India

2 Water Research Centre, Kuwait Institute for Scientific Research, Kuwait City, Kuwait

3 Department of Applied Geology, Faculty of Engineering and Science, Curtin University Malaysia, CDT 250, 98009 Miri, Sarawak, Malaysia
Heavy metal pollution studies in relation to groundwater were initiated by several authors by using index for the evaluation of drinking water quality (Edet and Offiong 2002). Trace metals are released from numerous sources related to natural weathering, industrial, domestic and agricultural practices (Romic and Romic 2003), which adversely affect environment. Heavy metals are released into the water by the weathering process of crust materials (Sun et al. 2016). Disposal of domestic and municipal sewage, industrial wastes and the chemicals used for agriculture contributes heavy metals to the groundwater (Alloway and Jackson 1991). The infiltration of various trace elements to the aquifers may create several health issues, if the same water is consumed by human beings (Karim 2011). The risk of contaminated water in regard to heavy metals and its influence to human health can be more in places with arid and semi-arid climates like the proposed study area. The main source of livelihood of this study area is relying on agriculture, and thus, utilization of composts and pesticides makes the groundwater assets more vulnerable toward contamination of heavy metals. Moreover, this proposed area is a tourist place so the demand for fresh water is more as utilized for drinking and other household purpose. Some published work on heavy metal contamination is limited only up to Tuticorin (Thoothukudi) District, which is located in the eastern part of the study area (Puthiyasekar et al. 2010; Selvam et al. 2015). Thus, the regulation of heavy metal pollution in the proposed study area is needed, as there is no previous record available. The main aim of this study is to compare the heavy metal levels 
in groundwater with respect to international standard and the possible impact of drinking water on human health by determining risk index. Further, the study calculates the pollution indices and clusters the samples using statistical analysis to compare with land-use and lithology to determine the probable sources of metals.

\section{Study area}

Tirunelveli District is located in the southern part of Tamil Nadu state of South India. It is surrounded with Virudhunagar District to the north, Tenkasi District to the west, Kanyakumari District to the south and Thoothukudi District to the east. The proposed area lies at northwestern portion of Tirunelveli District, Tamil Nadu, India, and falls between the North latitudes $8.834^{\circ}$ to $9.328^{\circ}$ and East longitudes $77.155^{\circ}$ to $77.527^{\circ}$ extending over $1789 \mathrm{Sq} \mathrm{km}$ (Fig. 1). Number of waterfalls clustered in this region attracts tourist and results in an increased urbanization as well as water demand. The normal average rainfall received in this region is about of $917.88 \mathrm{~mm} /$ year as reported by CGWB (2009) after evaluating for a period from 1991 to 2007. Northeast monsoon (NEM) contributes $70 \%$ of total annual rainfall; however, the rest is contributed by southwest monsoon (SWM) including few summer showers (Subramani et al. 2005). The water level starts increasing during NEM (November and December) and rises high in January and further decreases from February until September or October. Water level variation for a period from 1991 to 2007 has been noted by CGWB (2009) indicating its increase and decrease at a range from 0.0021 to $1.1284 \mathrm{~m} /$ year and 0.016 to $0.689 \mathrm{~m} /$ year, respectively. The average temperature of the region varies in between 28 to $37{ }^{\circ} \mathrm{C}$ with a parched to semiparched climate (CGWB 2009). Generally, the study area has a hilly topography, sloping toward the southeast with a variation of height from 150 to $1700 \mathrm{~m}$ above mean sea level (amsl). The major lithological units of this terrain are fissile hornblende biotite gneisses (FHBG) and charnockite. The agronomic lands cover almost $60 \%$ of the total area along with forestry $(17.41 \%)$, surplus land (14.27\%), water bodies (6.31\%) and buildup land $(3.50 \%)$ (Banajarani et al. 2017). Intensive agricultural practices and pastures are noted along the mountain front. However, mountains are predominantly of forestry. Chittar is the main non-perennial river in this area, which originated from the Courtallam Hills, in Poigaimalai Hill ranges of Western Ghats and mainly dependent on NEM for water (Banajarani et al. 2017).

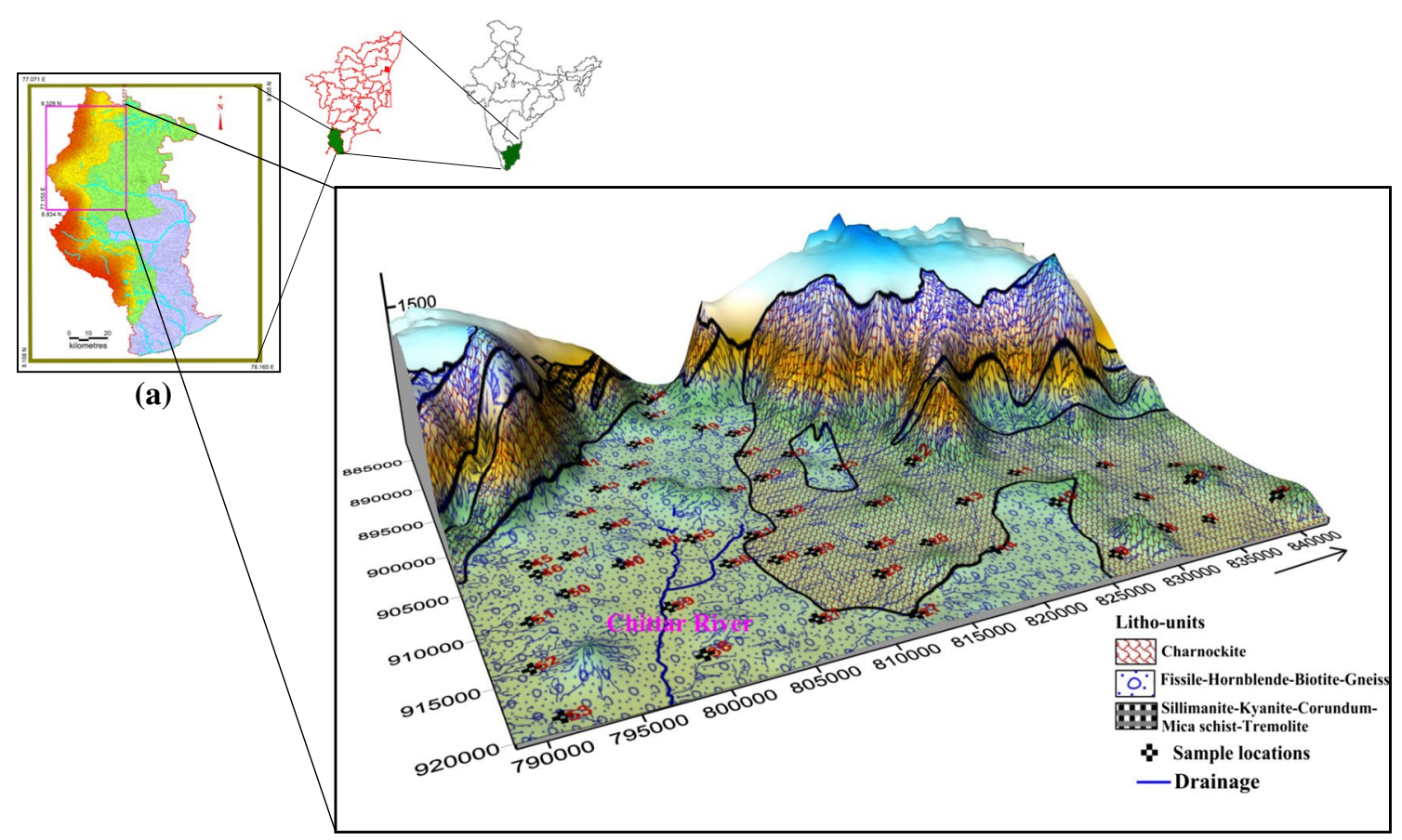

(b)

Fig. 1 Location map of the study area a elevation map in 2D view, b elevation map in 3D view along with lithology, drainage and sample locations 


\section{Materials and Methods}

\section{Sampling and Analysis}

Overall 53 number of groundwater samples were collected during POM. $200 \mathrm{ml}$ polythene bottles were used to collect the water sample. At first, the sample container was flushed with the same water to be tested and then collected in the same container. The collected samples were acidified with conc. $\mathrm{HNO}_{3}$. These samples were brought to the laboratory and stored at a temperature of $4{ }^{\circ} \mathrm{C}$ up to the analysis. Sixteen trace elements: $\mathrm{Li}, \mathrm{Be}, \mathrm{Al}, \mathrm{Ti}, \mathrm{Cr}, \mathrm{Fe}, \mathrm{Mn}$, $\mathrm{Cu}, \mathrm{Cd}, \mathrm{Zn}, \mathrm{Ga}, \mathrm{Rb}, \mathrm{Sr}, \mathrm{Cs}, \mathrm{Ba}$ and $\mathrm{Pb}$ were measured by ICPMS (0731293 iCAP RQ Quadrupole ICP-MS Spectrometer with 1 QCell MFC and a $1000 \mathrm{~mL} / \mathrm{min}$, detection limit: 0.5-1000 ng/L) (Centralized Instrumentation and Service Laboratory (CISL), Annamalai University).

\section{Calculation of health index values}

The equation to compute chronic daily intake (CDI) (modified after US EPA 1999) is

$\mathrm{CDI}=C * \mathrm{DI} / \mathrm{BW}$

where $C$, DI and BW stand for the amount of heavy metal $(\mu \mathrm{g} / \mathrm{L})$, daily intake rate on an average $(2 \mathrm{~L} /$ day $)$ for adult $(72 \mathrm{~kg}$ ) and $1 \mathrm{~L} /$ day for child $(32.7 \mathrm{~kg}$ ) (Nawab et al. 2016). To assess the health risks, the accompanying equation can be utilized to figure the health risk index (HRI):

$\mathrm{HRI}=\mathrm{CDI} / \mathrm{RFD}$

where the RFD is the reference dosage of the trace elements for intake. The HRI is safe if (HRI < ) (Muhammad et al. 2016).

A weightage (in between 0 and 1 ) for every selected element was assigned by heavy metal pollution index (HPI), which is indirectly proportional to the standard acceptable value $\left(S_{i}\right)$. This can be obtained by HPI $=\frac{\sum_{i=1}^{n} W i Q i}{\sum_{i=1}^{n} W i}$

(Mohan et al. 1996). [Qi: sub-index of the $i^{\text {th }}$ parameter; $W i: i^{\text {th }}$ parameter's weight; $n$ : number of considered elements]

The $Q i$ is obtained by using the equation:

$Q i=\sum_{i=1}^{n} \frac{\{M i(-) I i\}}{S i-I i} \times 100$

[Mi: monitored metal; $I i$ : ideal and Si: standard of the $i$ th parameter. (-): difference between two values (neglecting the numerical sign)].

The $S i$ and $I_{i}$ of each element are assigned according to BIS (2012) standard.
Heavy metal evalution index (HEI) is obtained by the following expression (Edet and Offiong 2002):

$\mathrm{HEI}=\sum_{i=1}^{n} \frac{\mathrm{Hc}}{\mathrm{Hmac}}$

[Hc: monitored value and Hmac: maximum admissible concentration (MAC) of ith parameter]

The contamination index $\left(C_{\mathrm{d}}\right)$ is calculated as follows (Backman et al. 1997):

$C_{d}=\sum_{i=1}^{n} \mathrm{Cf} i$

where $\mathrm{Cf}_{i} \frac{\mathrm{CA} i}{\mathrm{CN} i}-1$ [Cfi: contamination factor; Cai: analytical value and $\mathrm{CN} i$ : upper permissible concentration of $i$ th parameter/MAC in which $N$ : normative value].

Different principles for HPI, HEI and $C_{\mathrm{d}}$ of the samples have been established, which is shown by their particular average values. The multiples of the average values are taken into considerations to demarcate the significant levels of contamination (Edet and Offiong 2002).

Q mode cluster analysis has been carried out to plot the dendrogram by using Ward's linkage method to determine the association of sample locations in different clusters and its origination sources.

\section{Result and discussion}

\section{Potentially toxic heavy metals and its health effects}

The analytical minimum, maximum and average value of trace metals in groundwater are listed in Table 1. The order of dominance based on their mean values is given below:

$$
\begin{aligned}
\mathrm{Ti} & >\mathrm{Fe}>\mathrm{Sr}>\mathrm{Zn}>\mathrm{Ba}>\mathrm{Al}>\mathrm{Mn}>\mathrm{Cr} \\
& >\mathrm{Cd}>\mathrm{Pb}>\mathrm{Rb}>\mathrm{Li}>\mathrm{Cu}>\mathrm{Cs}>\mathrm{Ga}>\mathrm{Be}
\end{aligned}
$$

Considering the maximum value, the water samples exceeded the relevant prescribed limits of WHO (2006) for drinking water for metals like $\mathrm{Li}, \mathrm{Ti}, \mathrm{Al}, \mathrm{Cr}, \mathrm{Fe}, \mathrm{Sr}, \mathrm{Cd}$, $\mathrm{Ba}$ and $\mathrm{Pb}$. However, the elements $\mathrm{Be}, \mathrm{Mn}, \mathrm{Cu}$ and $\mathrm{Zn}$ fall below the limit of WHO (2006). Ga, Rb and Cs elements are omitted from the WHO guideline as shown in Table 1, because its occurrence in drinking water is not of health concern at levels usually found (WHO 2006).

The percentage of the samples exceeding the permissible limit for these elements is described in Fig. 2.

Fe concentration in 58\% water samples exceeds the WHO (2006) acceptable limit. The abundance of Fe in Earth's Crust makes it an indispensable and non-conservative heavy metal in drinking water. The nutritional requirement of iron per day is estimated to be $10 \mathrm{mg}$. Iron deficiency in human 
Table 1 Maximum, minimum and mean concentration of trace elements, the mean CDI $(\mu \mathrm{g} / \mathrm{kg}$ bw per day) and HRI values of heavy metals in groundwater along with the WHO standard

\begin{tabular}{|c|c|c|c|c|c|c|c|c|c|}
\hline \multirow[t]{2}{*}{ Parameters } & \multirow[t]{2}{*}{ Avg (ppb) } & \multirow[t]{2}{*}{$\operatorname{Min}(\mathrm{ppb})$} & \multirow[t]{2}{*}{ Max (ppb) } & \multicolumn{2}{|l|}{ CDI } & \multirow{2}{*}{$\begin{array}{l}\mathrm{RfD}, \mu \mathrm{g} /(\mathrm{kg} / \mathrm{day}) \\
\text { (Shah et al. 2012; Muhammad } \\
\text { et al. 2016; US EPA 1992) }\end{array}$} & \multicolumn{2}{|l|}{ HRI } & \multirow{2}{*}{$\begin{array}{l}\text { WHO } \\
(2006) \\
\text { Standard }\end{array}$} \\
\hline & & & & Adult & Children & & Adult & Children & \\
\hline $\mathrm{Li}$ & 6.38 & 0.74 & 92.92 & 0.2180 & 0.2400 & $2.00 \mathrm{E}+00^{\#}$ & $1.10 \mathrm{E}-01$ & $1.20 \mathrm{E}-01$ & $* * 10$ \\
\hline $\mathrm{Be}$ & 0.01 & 0.00 & 0.05 & 0.0003 & 0.0003 & $2.00 \mathrm{E}+00$ & $1.33 \mathrm{E}-04$ & $1.47 \mathrm{E}-04$ & ${ }^{* \#} 0.08$ \\
\hline $\mathrm{Al}$ & 84.03 & 11.23 & 378.09 & 2.3978 & 2.6397 & $1.00 \mathrm{E}+03$ & $2.40 \mathrm{E}-03$ & $2.64 \mathrm{E}-03$ & 50 to 200 \\
\hline $\mathrm{Ti}$ & 11200.53 & 0.00 & 42823.43 & 321.4 & 353.88 & $300^{\# \#}$ & 1.07 & 1.18 & $1080^{@}$ \\
\hline $\mathrm{Cr}$ & 32.21 & 4.00 & 87.14 & 0.5647 & 0.6216 & $1.50 \mathrm{E}+03$ & $3.76 \mathrm{E}-04$ & $4.14 \mathrm{E}-04$ & *50 \\
\hline $\mathrm{Mn}$ & 35.77 & 0.34 & 261.35 & 0.7461 & 0.8214 & $1.40 \mathrm{E}+02$ & $5.33 \mathrm{E}-03$ & $5.87 \mathrm{E}-03$ & *500 \\
\hline $\mathrm{Fe}$ & 4682 & 0 & 30801 & 145.7 & 160.4 & $8250^{\# \# \#}$ & $1.77 \mathrm{E}-02$ & $1.94 \mathrm{E}-02$ & 50 \\
\hline $\mathrm{Cu}$ & 2.64 & 0.00 & 20.00 & 0.0568 & 0.0625 & $3.70 \mathrm{E}+01$ & $1.53 \mathrm{E}-03$ & $1.69 \mathrm{E}-03$ & ${ }^{*} 2000$ \\
\hline $\mathrm{Zn}$ & 188.45 & 1.01 & 2969.09 & 6.3535 & 6.9947 & $3.00 \mathrm{E}+02$ & $2.12 \mathrm{E}-02$ & $2.33 \mathrm{E}-02$ & 3000 \\
\hline $\mathrm{Ga}$ & 0.03 & 0.00 & 0.10 & 0.0006 & 0.0006 & & & & NA \\
\hline $\mathrm{Rb}$ & 7.01 & 1.04 & 36.43 & 0.2064 & 0.2273 & & & & NA \\
\hline $\mathrm{Sr}$ & 1508.44 & 64.81 & 5970.00 & 43.42 & 47.81 & 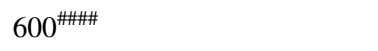 & $7.20 \mathrm{E}-02$ & $7.90 \mathrm{E}-02$ & ${ }^{* \#} 4000$ \\
\hline $\mathrm{Cd}$ & 13.23 & 0.01 & 438.43 & 0.053 & 0.059 & $5.0 \mathrm{E}-01$ & $1.06 \mathrm{E}+00$ & $1.18 \mathrm{E}+00$ & 3 \\
\hline Cs & 0.06 & 0.01 & 0.17 & 0.0016 & 0.0018 & & & & NA \\
\hline $\mathrm{Ba}$ & 181.54 & 6.42 & 1052.69 & 5.39 & 5.94 & $7.00 \mathrm{E}+01$ & $7.71 \mathrm{E}-02$ & $8.48 \mathrm{E}-02$ & 700 \\
\hline $\mathrm{Pb}$ & 7.86 & 0.00 & 44.58 & 0.2328 & 0.2563 & $3.60 \mathrm{E}+01$ & $6.47 \mathrm{E}-03$ & $7.12 \mathrm{E}-03$ & *10 \\
\hline
\end{tabular}

$P$ provisional guideline value, as there is evidence of a hazard, but the available information on health effects is limited; $T$ provisional guideline value because calculated guideline value is below the level that can be achieved through practical treatment methods, source protection, etc.; $C$ concentrations of the substance at or below the health-based guideline value may affect the appearance, taste or odor of the water, resulting in consumer complaints

*WHO (2011); ${ }^{* \#}$ MDH (1999); ${ }^{* *}$ Lenntech (2017); ${ }^{@}$ Dong et al. 1993; *NA-Not of health concern at levels usually found in drinking water

\# USEPA (2008); ${ }^{\# \# ~ N S F ~(2005) ; ~}{ }^{\# \# \# ~ B u r a n a t r e v e d h ~(2014) ; ~ \# \# \# \# ~ U S E P A ~(1992) ~}$

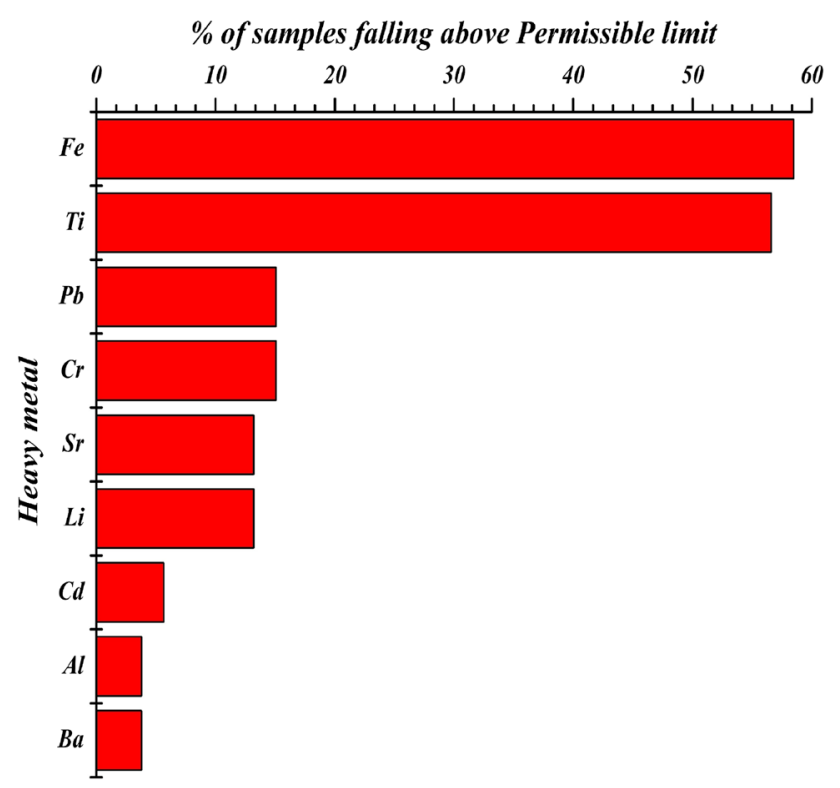

Fig. 2 Percentage of samples falling above the permissible limit of the drinking water standard

beings causes a disease called "anemia," and on the other hand, continued ingestion of drinking water with elevated iron may lead to liver disease called as hermosiderosis (Rajgopal 1984).

Ti concentration in $56.6 \%$ water samples exceeds the WHO (2006) acceptable limit. Titanium halogen intake causes nausea and vomiting and acidifies the body after resorption. Corrosion occurs at eye or skin contact, or when it comes in contact with mucous membranes (Lenntech (2017).

Fifteen percentage of total water samples exceeds the acceptable limit for $\mathrm{Pb}$ (WHO 2006). Exposure to $\mathrm{Pb}$ can cause an extensive variety of medical issues like renal disappointment, coma, digestion problem, intelligence to convulsions and even death (Papanikolaou et al. 2005). As indicated by IARC (2012), inorganic $\mathrm{Pb}$ compounds are perhaps cancer-causing to people and categorized in Group 2A.

Fifteen percentage of total water samples exceeds the acceptable limit for $\mathrm{Cr}$ (WHO 2006). Health effects due to higher consumption of $\mathrm{Cr}$ include cancer, gastrointestinal disorders, etc. Upon ingestion, $\mathrm{Cr}^{6}$ creates gastric problems, stomach ulcers, liver damage and kidney dysfunction (Beaumont et al. 2008). 
Thirteen percentage of total water samples exceeds the permissible limit for $\mathrm{Sr}$ (WHO 2006). There is no proof that drinking water with trace amount of $\mathrm{Sr}$ is unsafe. In any case, introduction to elevated amounts of normally happening Sr during early stages and adolescence can influence bone development and cause dental changes, and there is some proof that $\mathrm{Sr}$ increases bone density in adults. The isotope strontium- 90 has been connected to bone tumors and leukemia. $\mathrm{Sr}$ is found to be chemically more active than $\mathrm{Ca}$; hence, $\mathrm{Sr}$ can effortlessly substitute $\mathrm{Ca}$ in human bones. But Sr constituents tend to be weak, thus making such bones fragile. Consequently, the replacement of $\mathrm{Ca}$ by $\mathrm{Sr}$ can be very hazardous owing to its radio activity as well (Skoryna 1981). Strontium uptake has no reported threat to human health. The single Sr compound which is toxic, even in small amounts, is strontium chromate. Strontium chromate is shown to cause lung cancer (Skoryna 1981).

Li concentration in $13 \%$ water samples exceeds the permissible limit as given in Fig. 2. On an average, lithium content of about 2 milligrams per day enters human body through food with the principal source being grains and vegetables. The body processes lithium through the kidneys or in our excrement. $\mathrm{Li}$ in desirable quantities is used to treat mental disorders (Voutchkova et al. 2015). 10 ppm lithium carbonate in blood is less risky; however, at $15 \mathrm{ppm}$, one encounters disarray and speech impairment. At $20 \mathrm{ppm}$, there is a danger of lethality (Lenntech 2017).

Six percentage of total water samples exceeds the acceptable limit for Cd (WHO 2006). Cd is cancer-causing to individual and classified as Group 1 by International Agency for Research on Cancer (IARC). Cd causes lungs cancer, and the investigation has indicated positive connection for kidney and prostate cancer also (IARC 2012). High ingestion of Cd can cause kidney, pneumonic and skeletal harms (Godt et al. 2006).

Four percentage of total water samples exceeds the acceptable limit for $\mathrm{Al}$ and $\mathrm{Ba}$ (WHO 2006). Absorption of about $10 \mu \mathrm{g}$ of $\mathrm{Al}$ per day is harmless to humans. Large aluminum intake may cause nerve and kidney damage (Lenntech 2017). There is a danger of hypersensitivities. $\mathrm{Al}$ is likely mutagenic and cancer-causing. Elevated intake of aluminum may cause osteomalacia (vitamin D and calcium deficiencies). Al particles may cause utilitarian lung issue. No known diseases are connected to $\mathrm{Al}$ deficiencies (Lenntech 2017). $\mathrm{AlCl}_{3}$ can decompose the skin, irritate the mucous layers in the eyes and cause sweat, shortness of breath and coughing. Alum enhances blood coagulating (Lenntech 2017).

The health impacts of Ba rely on the water solvency. The dissolved compounds in water comprising of $\mathrm{Ba}$ can be destructive to human health. The uptake of a lot of $\mathrm{Ba}$ that are water-solvent may cause deadens and, at times, even demise (Lenntech 2017). Little measures of water-solvent barium may make a man encounter breathing troubles, elevated blood pressure, muscle weakness and changes in nerve reflexes (Lenntech 2017).
Fig. 3 The mean CDI $(\mu \mathrm{g} /$ $\mathrm{kg}$ - bw per day) values and HRI of heavy metals considered for drinking water purpose
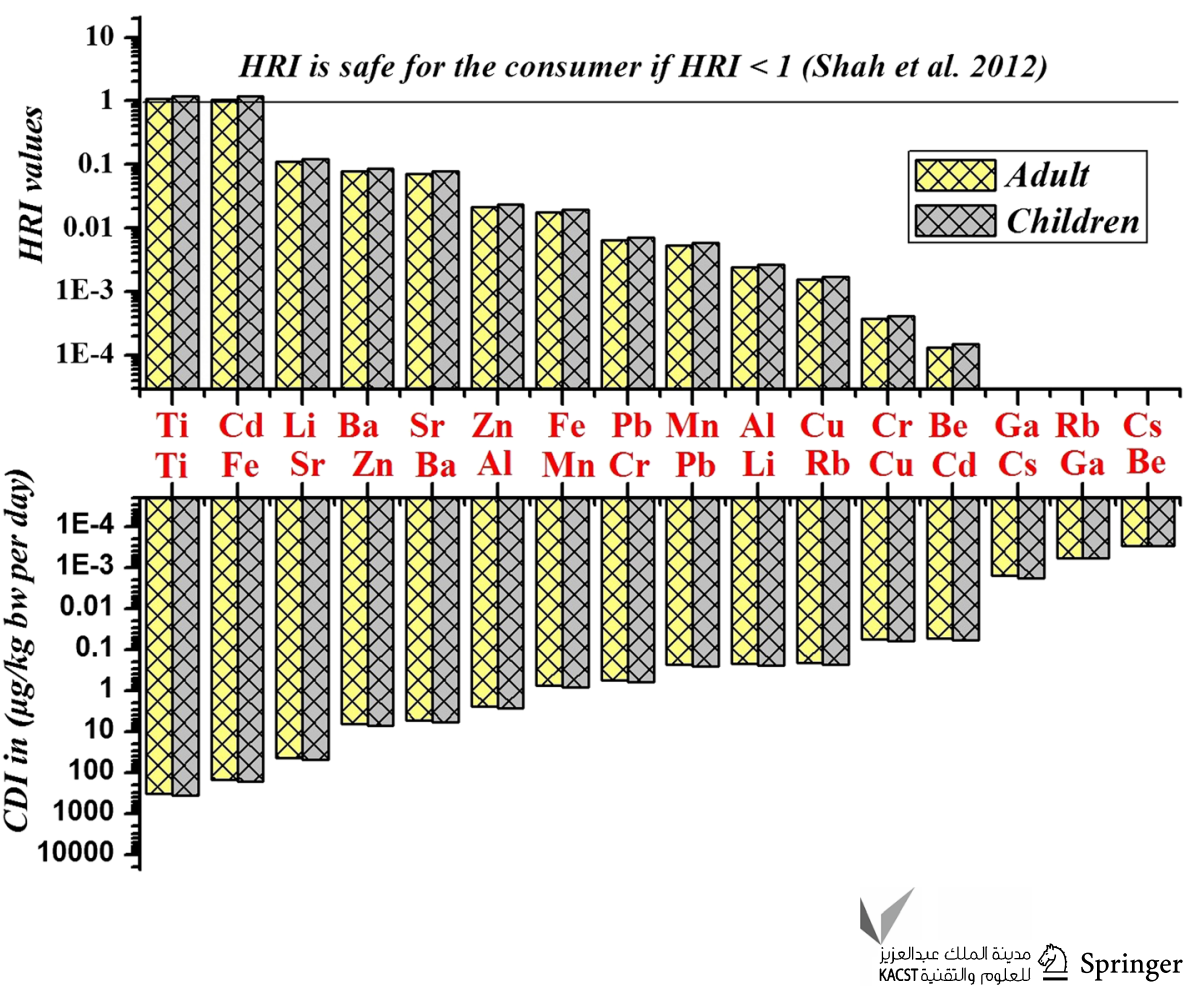


\section{Human health risk assessment}

\section{Chronic daily intake (CDI) and health risk index (HRI) of metals}

The CDI and HRI values for the toxic metals are summarized in Fig. 3. The average values of CDIs for the metals are found in the order of $\mathrm{Ti}>\mathrm{Fe}>\mathrm{Sr}>\mathrm{Zn}>\mathrm{Ba}>\mathrm{Al}>\mathrm{Mn}>\mathrm{Cr}$ $>\mathrm{Pb}>\mathrm{Li}>\mathrm{Rb}>\mathrm{Cu}>\mathrm{Cd}>\mathrm{Cs}>\mathrm{Ga}>\mathrm{Be}$ for both adults and children. The highest CDI mean value for both adults and children is noted for Fe, however, lowest for Be. The CDI values for all the elements in the study area appeared lesser except Fe, Ti, Sr, Zn and Ba.

The HRIs of selected heavy metals on the basis of water quality are found in the order of $\mathrm{Ti}>\mathrm{Cd}>\mathrm{Li}>\mathrm{Ba}>\mathrm{Sr}>$ $\mathrm{Zn}>\mathrm{Fe}>\mathrm{Pb}>\mathrm{Mn}>\mathrm{Al}>\mathrm{Cu}>\mathrm{Cr}>\mathrm{Be}$ for both adult and children. The data in Fig. 3 demonstrate that predominantly the HRI values in this study are within safe limits $(\mathrm{HRI}<1)$, suggesting no health risk in this region (Muhammad et al. 2016) except $\mathrm{Ti}$ and $\mathrm{Cd}$. However, the HRIs of $\mathrm{Li}, \mathrm{Fe}$ and Mn are higher in this study compared to other elements.

\section{Pollution indices}

\section{Heavy metal pollution index (HPI)}

Pollution indices are used to obtain the influence of all metals to the overall pollution of a region. The HPIs are used to obtain the impact of all analyzed metals on the overall pollution of a region. HPI of all the individual sample has been calculated based on BIS (2012) standard. It ranges from 1.26 to 228.59 with a mean value of 39.54 . The different contamination level of HPI has been derived by acquiring the mean approach as suggested by Edet and Offiong (2002) such as low (HPI < 40), medium (HPI = 40-80) and high (HPI>80) (Table 2). Thirty-eight samples $(71.69 \%$ ) are falling in low category, i.e., having HPI lesser than the mean value, which signifies a pollution free status of the water related to metals
(Prasad and Bose 2001). 7 and 8 number of samples are falling in medium and high pollution index, respectively.

\section{Heavy metal evaluation index (HEI)}

The HEI helps to understand the pollution in an improved way (Edet and Offiong 2002). In the present study, the HEI value ranges from 0.27 to 124.26 with a mean value of 28.03. Considering the calculation based on mean values as suggested by Edet and Offiong (2002), for the present study, the HEI values are divided into 3 groups: low (HEI $<28)$, medium $(\mathrm{HEI}=28-56)$ and high $(\mathrm{HEI}>56)$. Thirty $(56.6 \%)$ samples fall in the low class, i.e., below the respective mean values. Table 2 shows that 6 (11.32\%) samples have higher values and these samples are observed along the southern, northwestern and central portion of the study area.

\section{Degree of contamination $\left(C_{\mathrm{d}}\right)$}

The range of metal pollution of a region can be estimated by $C_{\mathrm{d}}$ (Al-Ami et al. 1987). In the proposed study, it ranges from 0.28 to 113.26 with a mean value of 23.28 . $C_{\mathrm{d}}$ is classified into 3 categories: low $\left(C_{\mathrm{d}}<23\right)$, medium $\left(C_{\mathrm{d}}=23-46\right)$ and high $\left(C_{\mathrm{d}}>46\right)$ following the mean approach similar to HPI and HEI as suggested by Edet and Offiong (2002) (Table 2). Five samples $(9.43 \%$ ) are classed in high contamination zone which are observed along the southern and northwestern part of the study area.

It is also interesting to note that the samples showing low pollution index for HEI, i.e., below the respective mean value also, have $C_{\mathrm{d}}$ and HPI value lower than their respective mean, suggesting relatively better water quality as observed by Prasad and Bose (2001).

Further, the critical pollution index value of HPI is 100 (Prasad and Bose 2001). Thus, the samples falling in the higher category of HPI (Table 2) can be classed into high $(<100)$ and extremely high $(>100)$ contamination zone. Four samples $(12,13,40$ and 51) having HPI $<100$ are

Table 2 Classification of groundwater quality of the region based on categories of pollution indices

\begin{tabular}{llllll}
\hline Index & Category & Degree of pollution & No of samples & $\%$ & Samples \\
\hline HPI & $<40$ & Low & 38 & 71.69 & $1-9,15-24,26-37,44-50$ \\
& $40-80$ & Medium & 7 & 13.02 & $10,11,14,39,43,52,53$ \\
& $>80$ & High & 8 & 15.09 & $12,13,25,38,40,41,42,51$ \\
HEI & $<28$ & Low & 30 & 56.60 & $3,4,14-19,21-24,26-37,44,46-50$ \\
& $28-56$ & Medium & 17 & 32.07 & $1,2,6-13,20,39,40,43,45,52,53$ \\
& $>56$ & High & 6 & 11.32 & $5,25,38,41,42,51$ \\
Cd & $<23$ & Low & 32 & 60.37 & $3,4,7,11,14-19,21-24,26-37,44,46-50$ \\
& $23-46$ & Medium & 16 & 30.18 & $1,2,6,8-10,12,13,20,39,40,43,45,51-53$ \\
& $>46$ & High & 5 & 9.43 & $5,25,38,41,42$ \\
\hline
\end{tabular}




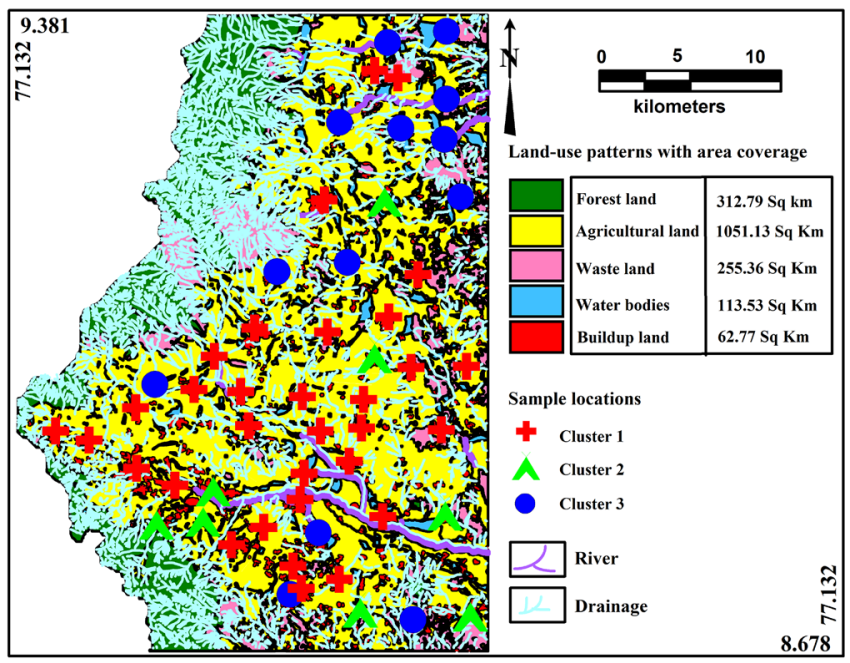

(a)

Fig. 4 a Land-use and drainage map along with the sample locations of the 3 clusters, $\mathbf{b}$ land-use pattern and sample locations with their HPI values, c dendrogram obtained by cluster analysis using Ward's

observed along the southern and northwestern part of the study area (Fig. 4b). However, remaining 4 samples $(25,38$, $41,42)$, i.e., $7.54 \%$, are above critical index value $(>100)$, noted along the southern and central part of the study area (Fig. 4b). It is also interesting to note that these same samples $(25,38,41,42)$ have high $\mathrm{HEI}$ and $\mathrm{C}_{\mathrm{d}}$ values which signifies extremely polluted status of water (Prasad and Bose 2001). These 4 samples are located in the vicinity of urban (residential) region. Large volume of waste water is being discharged from the sewage system, and open waste disposal sites of urban area to the water bodies may induce the release of more metals into the groundwater.

\section{Cluster analysis for source identification}

Hierarchical cluster analysis has been carried out to understand the sample grouping in the dataset with three clusters (Fig. 4c). Samples belong to same cluster are believed to have same source of origination (Prasanna et al. 2012). Clusters 1, 2 and 3 are represented by 32, 8 and 13 number of samples, respectively. Cluster 1 samples are spatially distributed in the southern part along the foothills and river, which is flowing from SW-SE direction (Fig. 4a). Major portion of the region is covered with agricultural land. Thus, intensive agricultural practices and applications of fertilizers and pesticides may contribute continuous leaching of heavy metals to the surface water (river) (Alloway and Jackson 1991). Fertilizers also comprise of heavy metals like Cd, $\mathrm{Cu}$ and $\mathrm{Zn}$. Heavy metals like $\mathrm{Pb}$ and $\mathrm{Fe}$ are the active compounds of pesticides (Eugenia et al. 1996). Thus, infiltration

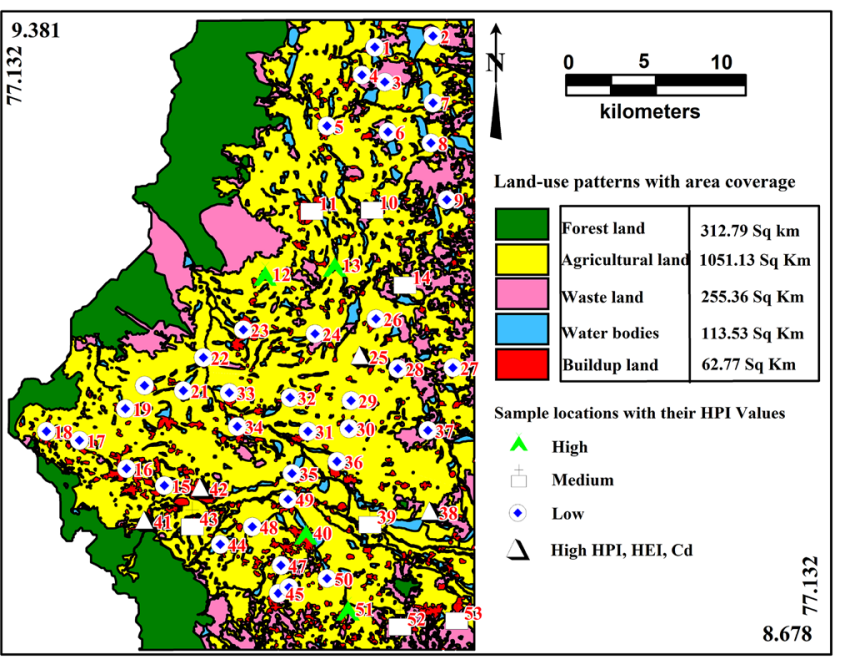

(b)

linkage. HPI heavy metal pollution index, HEI heavy metal evaluation index, $C d$ degree of contamination

of surface water which contains these heavy metals can leach into groundwater.

Cluster 2 samples are mainly distributed along the southern part, and one sample is falling in northern, and the other is along the central part of the study area (Fig. 4a). It is interesting to note that these samples are located in the vicinity of urban areas. Thus, the groundwater in these regions gets affected by the sewage effluents, landfill leachates and cesspool salts (Biney and Christopher 1991). Large amount of water is being released from the sewage system and open disposal sites, which infiltrate into the sub-surface aquifer. The practice of discharge of waste from untreated municipal sewage into the aquatic system leads to the increase in the concentration of heavy metals in water of these regions (Martín et al. 2015).

Cluster 3 samples are spatially distributed in the northern part of the study area, and only 3 samples are falling in the foothills of southern side (Fig. 4a). The samples along the northern side are noted along the Charnockitic terrain (Fig. 1) which signifies that these samples may have geogenic source. It is also interesting to note that the southern side samples are falling near to the foothills of the mountain which is predominantly of charnockites. Thus, it is inferred that the heavy metals are released by the weathering/leaching of charnockites. Natural weathering of granites, charnockites and other igneous rocks accumulate $\mathrm{Sr}, \mathrm{Ba}, \mathrm{Li}, \mathrm{Cr}$, $\mathrm{Ti}$ and $\mathrm{Fe}$ in the environment (Muhammad et al. 2016). Ba and $\mathrm{Sr}$ are less soluble than $\mathrm{Ca}$ and $\mathrm{Mg}$, but found in appreciable quantities in the igneous rocks (Pekey et al. 2004). Thus, locations in northern part may be directly influenced by the weathering/leaching of charnockites; however, in the southern part samples, geogenic leachates move laterally

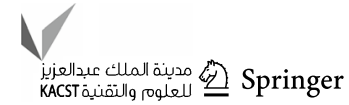




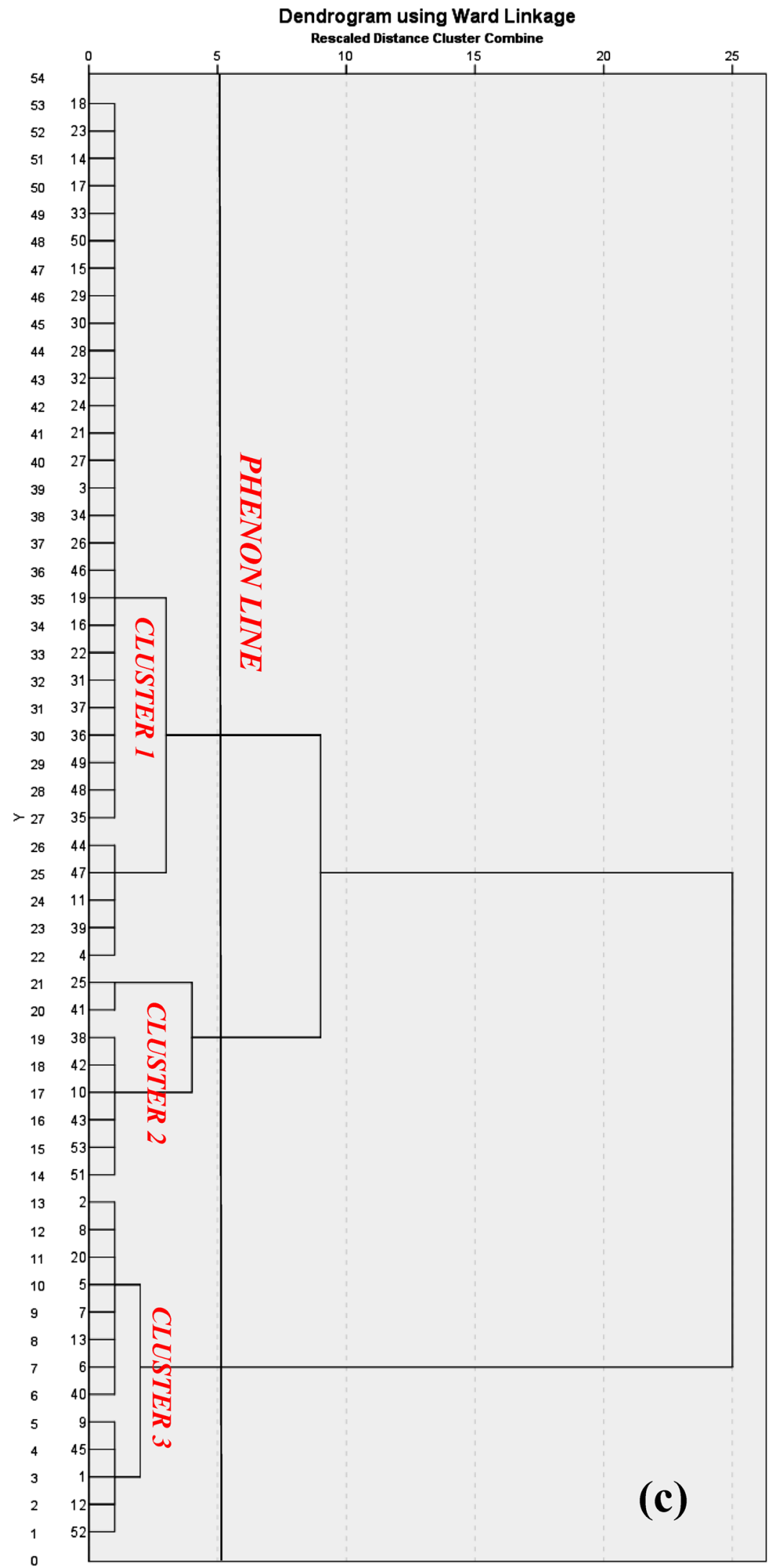

Fig. 4 (continued) 
along the groundwater flow direction (SW-SE) and add to the mountain front aquifer.

\section{Conclusion}

The study illustrates that the average concentration of heavy metal shows the following order of dominance $\mathrm{Ti}>\mathrm{Fe}>\mathrm{Sr}>$ $\mathrm{Zn}>\mathrm{Ba}>\mathrm{Al}>\mathrm{Mn}>\mathrm{Cr}>\mathrm{Cd}>\mathrm{Pb}>\mathrm{Rb}>\mathrm{Li}>\mathrm{Cu}>\mathrm{Cs}>\mathrm{Ga}$ $>\mathrm{Be}$. The elements like $\mathrm{Li}, \mathrm{Ti}, \mathrm{Al}, \mathrm{Cr}, \mathrm{Fe}, \mathrm{Sr}, \mathrm{Cd}, \mathrm{Ba}$ and $\mathrm{Pb}$ are exceeding the WHO standard limit for drinking water. The average CDI value for the trace elements is highest for $\mathrm{Ti}$, and it is lowest for Be. The HRI value indicates the trace elements of the study area are in safe zone i. e $<1$ except $\mathrm{Ti}$ and $\mathrm{Cd}$ suggesting no health risk. Four samples $(12,13,40$ and 51) have HPI $>100$, i.e., above the critical index with high HEI and Cd value. These 4 samples fall in the southern part of the study area which is near to settlements, suggesting extremely polluted status of the water and mainly influenced by urban activities. The hierarchical cluster analysis for the sampling stations reveals three clusters with different source of origin of heavy metal. Cluster 1 , cluster 2 and cluster 3 are suspected to associate with agricultural activities, urban influence and natural weathering of source rocks (i.e., charnockites), respectively.

Acknowledgements The authors would like to thank, The Science and Engineering Research Board (SERB), New Delhi (No: SB/S4/ ES-699/2013), for providing necessary financial support to carry out this study, and the author Banajarani Panda wishes to express her sincere thanks to Department of Science and Technology for providing the Inspire fellowship (No: DST/INSPIRE Fellowship/[IF150615], October 27, 2015).

Open Access This article is licensed under a Creative Commons Attribution 4.0 International License, which permits use, sharing, adaptation, distribution and reproduction in any medium or format, as long as you give appropriate credit to the original author(s) and the source, provide a link to the Creative Commons licence, and indicate if changes were made. The images or other third party material in this article are included in the article's Creative Commons licence, unless indicated otherwise in a credit line to the material. If material is not included in the article's Creative Commons licence and your intended use is not permitted by statutory regulation or exceeds the permitted use, you will need to obtain permission directly from the copyright holder. To view a copy of this licence, visit http://creativecommons.org/licenses/by/4.0/.

\section{References}

Abolude DS, Davies OA, Chia AM (2009) Distribution and concentration of trace elements in Kubanni reservoir in Northern Nigeria. Res J Environ Earth Sci 1(2):39-44

Al-Ami MY, Al-Nakib SM, Ritha NM, Nouri AM, Al-Assina A (1987) Water quality index applied to the classification and zoning of Al-Jaysh canal, Bagdad, Iraq. J Environ Sci Health 22:305-319

Alloway BJ, Jackson AP (1991) The behaviour of heavy metals in sewage sludge-amended soils. Sci Total Environ 100:151-176
Backman B, Bodis D, Lahermo P, Rapant S, Tarvainen T (1997) Application of a groundwater contamination index in Finland and Slovakia. Environ Geol 36:55-64. https://doi.org/10.1007/ s002540050320

Banajarani P, Chidambaram S, Ganesh N (2017) An attempt to understand the subsurface variation along the mountain front and riparian region through geophysics technique in South India. Model Earth Syst Environ. https://doi.org/10.1007/s40808-017-0334-8

Beaumont JJ, Sedman RM, Reynolds SD, Sherman CD, Li LH, Howd RA, Alexeeff GV (2008) Cancer mortality in a Chinese population exposed to hexavalent chromium in drinking water. Epidemiology 19(1):12-23

Biney CA, Christopher AB (1991) Trace metal concentrations in fish and sediments from the WIWI: a small urban river in Kumasi, Ghana. Trop Ecol 32(2):197-206

BIS (2012) Drinking water specifications 2nd revision. Bureau of Indian Standards (IS 10500: 2012). New Delhi. ftp://law.resou rce.org/in/ bis/S06/is.10500.2012.pdf (2012)

Buranatrevedh S (2014) Health risk assessment of general populations exposed to metals from an aluminium production plant in Thailand. J Commun Med Health Educ 4:262

CGWB (2009) District groundwater brochure Tirunelveli district, Tamil Nadu. Technical report series, 5

Dong SZ, Chen CZ, Li DM, Sun YS (1993) A study of hygienic standard for titanium in the source of drinking water. Zhonghua yu fang yi xue za zhi [Chin J Prev Med] 27(1):26-28

Edet AE, Offiong OE (2002) Evaluation of water quality pollution indices for heavy metal contamination monitoring. A study case from Akpabuyo-Odukpani area, lower cross river Basin (southeastern Nigeria). GeoJournal 57:295-304

Eugenia GG, Vicente A, Rafael B (1996) Heavy metals incidence in the application of inorganic fertilizers and pesticides to rice farming soils. Environ Pollut 92:19-25

Godt J, Scheidig F, Grosse-Siestrup C, Esche V, Brandenburg P, Reich A, Groneberg DA (2006) The toxicity of cadmium and resulting hazards for human health. J Occup Med Toxicol 1(1):1-6

IARC (2012) International Agency for Research on Cancer. A review of human carcinogens: arsenic, metals, fibres, and dusts. IARC monographs on the evaluation of carcinogenic risks to humans, vol 100C. IARC, Lyon, pp 121-141

Karim Z (2011) Risk assessment of dissolved trace metals in drinking water of Karachi, Pakistan. Bull Environ Contam Toxicol 86(6):676-678

Khan K, Lu Y, Khan H, Zakir S, Ullah I, Khan S, Khan AA, Luo W, Tieyu W (2013) Health risks associated with heavy metals in the drinking water of Swat, northern Pakistan. J Environ Sci 25:2003-2013. https://doi.org/10.1016/s1001-0742(12)60275-7

Lenntech (2017) Periodic table. http://www.lenntech.com/periodic/ elements. Accessed 30 Jan 2017

Martín JR, De Arana C, Ramos-Miras JJ, Gil C, Boluda R (2015) Impact of 70 years' urban growth associated with heavy metal pollution. Environ Pollut 196:156-163

MDH (1999) Screening evaluation of arsenic, cadmium, and lead levels in Minnesota fertilizer products. Minnesota Department of Health, St Paul

Mohan SV, Nithila P, Reddy SJ (1996) Estimation of heavy metal in drinking water and development of heavy metal pollution index. J Environ Sci Health A 31(2):283-289

Muhammad N, Banoori N, Akbar A, Azizullah A, Khan M, Qasim M, Rahman H (2016) Microbial and toxic metal contamination in well drinking water: potential health risk in selected areas of Kohat, Pakistan. Urban Water J 28:1-7

National Science Foundation (2005) Complex environmental systems: pathways to the future. http://www.nsf.gov/geo/ere/erewe b/news.cfm 
Nawab J, Khan S, Ali S, Sher H, Rehman Z, Khan K, Tang J, Ahmad A (2016) Risk assessment of heavy metals and biological contamination in drinking water of malakand agency, Northern Pakistan. Environ Monitor Assess 188:286. https:// doi.org/10.1007/s10661-016-5296-1

Papanikolaou NC, Hatzidaki EG, Belivanis S, Tzanakakis GN, Tsatsakis AM (2005) Lead toxicity update. A brief review. Med Sci Monitor 11(10):329-336

Pekey H, Karaka D, Bakoglu M (2004) Source apportionment of heavy metals in surface waters of a polluted stream using multivariate statistical analyses. Mar Pollut Bull 49:809-818

Prasad B, Bose JM (2001) Evaluation of the heavy metal pollution index for surface and spring water near a limestone mining area of the lower Himalayas. Environ Geol 41:183-188

Prasanna MV, Praveena SM, Chidambaram S, Nagarajan R, Elayaraja A (2012) Evaluation of water quality pollution for heavy metal contamination monitoring: a case study from Curtin Lake, Miri oCity, East Malaysia. Environ Earth Sci. https:// doi.org/10.1007/s12665012-1639-6

Puthiyasekar C, Neelakandan MA, Poongothai S (2010) Heavy metal contamination in bore water due to industrial pollution and polluted and non-polluted seawater intrusion in Thoothukudi and Tirunelveli of South Tamil Nadu, India. Bull Environ Contam Toxicol 85:598-601. https://doi.org/10.1007/s0012 8-010-0152-4

Rajgopal (1984) Ground-water quality assessment for public policy in India. First annual report. Department of Geography, IOWA Univeristy, IOWA

Romic M, Romic D (2003) Heavy metals distribution in agricultural topsoils in urban area. Environ Geol 43(7):795-805

Selvam S, Venkatramanan S, Singaraja C (2015) A GIS-based assessment of water quality pollution indices for heavy metal contamination in Tuticorin Corporation, Tamilnadu, India. Arab J Geosci 8:10611-10623. https://doi.org/10.1007/s12517-015-1968-3

Shah MT, Ara J, Muhammad S, Khan S, Tariq S (2012) Health risk assessment via surface water and sub-surface water consumption in the mafic and ultramafic terrain, Mohmand agency, northern Pakistan. J Geochem Explor 118:60-67. https://doi.org/10.1016/j. gexplo.2012.04.008

Skoryna SC (ed) (1981) Handbook of stable strontium. Plenum Press, NY, $644 \mathrm{pp}$
Subramani T, Elango L, Damodarasamy SR (2005) Groundwater quality and its suitability for drinking and agricultural use in Chithar River basin, Tamil Nadu, India. J Environ Geol 47:1099-1110

Sun L, Liu X, Min N (2016) Identifying the potential sources of trace metals in water from subsidence area based on positive matrix factorization. Water Pract Technol 11(2):279-287

Thuyet DQ, Saito H, Saito T, Moritani S, Kohgo Y, Komatsu T (2016) Multivariate analysis of trace elements in shallow groundwater in Fuchu in western Tokyo Metropolis, Japan. Environ Earth Sci 75(7):559

United States Environmental Protection Agency, USEPA (2008). Allowable limits for lead in soil. www.epa.gov/lead/pubs/leadh az.htm

US Environmental Protection Agency (US-EPA) (1999) Guidance for performing aggregate exposure and risk assessments. Office of Pesticide Programs, Washington

USEPA (US Environmental Protection Agency) (1992) Defi- nitions and general principles for exposure assessment. Guidelines for exposure assessment. Office of Pesticide Programs, Washington

Voutchkova DD, Schullehner J, Knudsen NN, Jørgensen LF, Ersbøll AK, Kristiansen SM, Hansen B (2015) Exposure to selected geogenic trace elements (I, $\mathrm{Li}$, and $\mathrm{Sr}$ ) from drinking water in Denmark. Geosciences 5(1):45-66

WHO (World Health Organization) (2006) Guidelines for drinking water quality, vol 1. First Addendum to third ed. Recommendations. WHO, Geneva

WHO (World Health Organization). (2011). Guidelines for drinkingwater quality (4th ed.). http://www.whqlibdoc.who.int/ publications/2011/9789241548151_eng.pdf. Accessed 15 Jan 2011

Wu B, Zhang Y, Zhang X, Cheng S (2010) Health risk from exposure of organic pollutants through drinking water consumption in Nanjing, China. Bull Environ Contam Toxicol 84:46-50

Publisher's Note Springer Nature remains neutral with regard to jurisdictional claims in published maps and institutional affiliations. 